\title{
A Structured Review of Quantitative Models of the Pharmaceutical Supply Chain
}

\author{
Carlos Franco $^{1,2}$ and Edgar Alfonso-Lizarazo ${ }^{3}$ \\ ${ }^{1}$ Universidad del Rosario, Escuela de Administración, Bogotá, Colombia \\ ${ }^{2}$ Universidad de La Sabana, School of Engineering, Group Logistic Systems, Campus Universitario, Puente del Común, Km. 7, \\ Autopista Norte, Bogotá, Colombia \\ ${ }^{3}$ University of Lyon, University Jean Monnet-St-Etienne, LASPI, EA3059, 42023 Saint-Etienne, France
}

Correspondence should be addressed to Carlos Franco; carlosa.franco@urosario.edu.co

Received 6 January 2017; Revised 2 November 2017; Accepted 6 November 2017; Published 5 December 2017

Academic Editor: Michele Scarpiniti

Copyright (c) 2017 Carlos Franco and Edgar Alfonso-Lizarazo. This is an open access article distributed under the Creative Commons Attribution License, which permits unrestricted use, distribution, and reproduction in any medium, provided the original work is properly cited.

\begin{abstract}
The aim of this review is to identify and provide a structured overview of quantitative models in the pharmaceutical supply chain, a subject not exhaustively studied in the previous reviews on healthcare logistics related mostly to quantitative models in healthcare or logistics studies in hospitals. The models are classified into three categories of classification: network design, inventory models, and optimization of a pharmaceutical supply chain. A taxonomy for each category is shown describing the principal features of each echelon included in the review; this taxonomy allows the readers to identify easily a paper based on the actors of the pharmaceutical supply chain. The search process included research articles published in the databases between 1984 and November 2016. In total 46 studies were included. In the review process we found that in the three fields the most common source of uncertainty used is the demand in the $56 \%$ of the cases. Within the review process we can conclude that most of the articles in the literature are focused on the optimization of the pharmaceutical supply chain and inventory models but the field on supply chain network design is not deeply studied.
\end{abstract}

\section{Introduction}

One of the objectives of a healthcare system is to guarantee access to medicines as a basic human right [1]. The pharmaceutical supply chain must provide the correct medicines in an adequate condition, to the right customer, at the right time and place, and at a minimum cost [2]. The high level of complexity in the healthcare sector is represented in the interactions between the various actors in the chain, including vendors, manufacturers, distributors, wholesalers, and providers $[3,4]$.

A typical configuration of a pharmaceutical supply chain includes a group of manufacturers which can be divided into five categories: multinational companies, generic manufacturers, local companies, contract manufacturers, and biotechnological companies [5]. Also included are a group of purchasers, including wholesalers and distributors, and a group of providers including hospitals, clinics, and pharmacies [3]. The activities of a pharmaceutical supply chain involve the flow and transformation of medicines from raw materials through to the end users; in addition, the associated information flows through the relationships in the supply chain to achieve a sustainable competitive advantage [6]. An illustrative example of a classical configuration is presented in Figure 1. It can be observed that medicines can be delivered directly from warehouses or the requirement also can be satisfied by the pharmacies.

In addition to the contribution of health services, the pharmacotherapeutic supply chain is an important contributor to the healthcare system [7]. The pharmaceutical industry is one of the most challenging industries in the world, since it is estimated that medicines consume about $20 \%-30 \%$ of global health spending [8]. However, pharmaceutical supply 


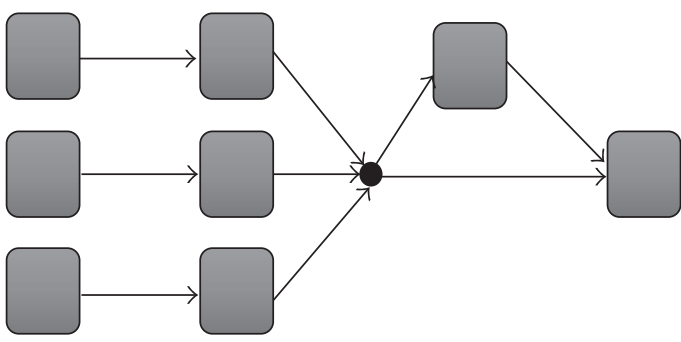

\begin{tabular}{|l|l|l|l|}
\hline Manufacturers & Wharehouses \\
\hline
\end{tabular}

FIgURE 1: Typical configuration of a pharmaceutical supply chain.

chain management is more difficult than typical applications within industrial companies, since medicines and surgical supplies must be available for use at all times [9].

It has been shown that the appropriate management of medicines and pharmaceutical products is directly related to the ability of a country to address public health concerns; it has also been identified that the management of pharmaceutical supplies is one of the most important managerial issues in healthcare industries [10].

Due to the complexity and the importance of the pharmaceutical supply chain, anything less than a service level of $100 \%$ is unacceptable, since this has a direct impact on public health. For this reason, one acceptable solution which can be adopted by a pharmaceutical supply chain is to carry a huge amount of inventory in order to ensure a fill rate close to $100 \%$. However, if a pharmaceutical company adopts this level of inventory, this increases the total costs assumed by the organization; it also represents a challenge since most of the medicines and products are perishable. It has been estimated that in supermarkets and drug stores the cost of expiration is over 500 million dollars per year [11]. In addition to the perishability of medicines, pharmaceutical supply chains deal with the problems of demand uncertainty, limitations of space, legal regulations, and patient safety.

The remainder of this paper is organized as follows. In Section 2 we describe several previous reviews and studies related to pharmaceutical supply chain management. The procedure used for the selection of papers is explained in Section 3. In Section 4, a description of the articles is presented, and finally Section 5 presents the conclusions of this review.

\section{Previous Reviews and Works Related to Pharmaceutical Supply Chain Management}

Laínez et al. [12] describe real mathematical applications which have immediate or potential relevance to the pharmaceutical industry. The article is divided into the three key phases in the lifecycle of an innovative drug product: product development, capacity planning, and supply chain management.

A study of the different areas of pharmaceutical supply chain management was completed by Kwon et al. [13].
This considers strategic areas in which the supply chain must achieve efficiency in terms of costs, such as supplier relationship management, logistics operational tools, and process improvement.

Another review has been carried out by [14] involving research on management issues in the pharmaceutical industry, and this study uses a classification in terms of geographical zones, research methodologies, and managerial issues. The study is not dedicated to finding quantitative models in the pharmaceutical supply chains except for the identification of emerging issues for healthcare practitioners.

A further study [15] identifies the 10 main global health supply chain challenges. The challenges are found to be lack of coordination, inventory management, absent demand information, human resource dependency, order management, shortage avoidance, expiration, warehouse management, temperature control, and shipment visibility. As a preliminary conclusion, it can be observed that this review contributes to the identification of at least four of the challenges mentioned above. Another point of view is presented by Alverson [16] in which the main challenges faced by pharmacies are divided into a lack of inventory control, excess inventory levels, frequent stock outages and costly emergency deliveries, increased health system labor requirements, workflow interruptions and expensive work, and missed contract compliance.

Shah [17] draws on the literature to present the most important issues in supply chain design and operation. Certain features addressed in the current article are mentioned, but the article also presents several points of view arising from the experience of the author in this field of research. It is important to mention that Shah presents a similar review of this work; however, the current study focuses on research on quantitative models in the various echelons of the pharmaceutical chain.

A recent review of material logistics in hospitals is presented by Volland et al. [18]. In this review, the logistical activities of hospitals are studied and several opportunities for future research are identified. Although this is not a study of quantitative models of pharmaceutical supply chain, some features of this study are similar to the current work, since this reviews inventory models.

In conclusion, there are some reviews that have developed different approaches to typify and characterize logistics problems in hospitals and medicines supply chains as material logistics in hospitals, supply chain design, and operations in hospitals or challenges in global health supply chain; nevertheless, this review has been focused on the quantitative models in the pharmaceutical supply chain, a subject not studied in depth in the previous reviews on healthcare logistics. Additionally, in this review process a new taxonomy is presented allowing the readers to identify easily a paper based on the actors of the pharmaceutical supply chain.

\section{Paper Selection Process}

3.1. Framework for Literature Classification. As the main objective of this review is focused on quantitative models on 
pharmaceutical supply chain, we have used the triangle of logistic strategy proposed by Ballou [19] as the framework for literature classification. Considering this triangle of logistic strategy, we identify and propose three major research topics within the literature for the quantitative models in the pharmaceutical supply chain: (1) design of the pharmaceutical supply chain network, (2) hospital inventories, and (3) optimization of pharmaceutical supply chain networks. The literature is thematically classified using this framework. Category (1) comprises the activities involved in the design of a supply chain network in the pharmaceutical sector; this includes the selection of a manufacturer's points and the capacity of production plants, warehouses, and distribution points. In research topic (2) we take into account decisions related to the inventory of medicines in hospitals and pharmacies. Finally, in category (3), models related to the optimization of a pharmaceutical supply chain are presented. The main difference between topics (1) and (2) is that, in the first topic, the decisions are related to considerations of strategy, while in the second topic decisions are made at an operational level for a distribution network.

3.2. Identification of Publications. In order to identify the relevant literature, relevant keywords were used to identify the principal articles. The keywords used for the first topic were "pharmaceutical supply chain network design," "pharmaceutical supply chain design," and "pharmaceutical multisite planning." For the second topic, the keywords used were "hospital inventories," "inventory hospitals," "pharmaceutical inventories," "medicine inventories," and "optimization inventory hospitals." Finally, the keywords used for the third topic were "pharmaceutical supply chain optimization," "optimization pharmaceutics," and "medicine optimization supply chain network."

The review was carried out using the following databases with English-language published papers: Informs Journals, Proquest, Sciencedirect, Springerlink, Taylor and Francis Group, Wiley Online Library, Emerald, and IEEExplore. The search process included research articles published in the databases mentioned before that meet any of the three fields of classification, published between 1984 and November 2016. The selection criteria of this review fall into two categories: first, papers that consider quantitative models for any echelon of the pharmaceutical supply chain presented in Figure 1 and second any type of paper or research focused on applications to pharmaceutical supply chain or the optimization of any stage of the logistics of medicines. In this way the inclusion criteria have the following characteristics: (i) original research developed that met any field of the taxonomy proposed in this research, (ii) paper written in English presented before in the range between 1984 and November 2016, (iii) research papers studying quantitative models and quantitative applications in the pharmaceutical supply chain, and (iv) papers listed in one of the databases mentioned before. The exclusion criteria have the following characteristics: (i) not being listed in the databases of quantitative methods or models or applications of quantitative models in healthcare or supply chain, (ii) qualitative studies in pharmaceutical supply chain management, (iii) case studies in pharmaceutical sector, (iv) quantitative models in supply chain that does not include any actor in the chain or does not belong to the taxonomy proposed.

\section{Review}

4.1. Supply Chain Network Design. The design of a supply chain network consists of the selection of the optimal logistical configuration of a new pharmaceutical supply chain. Decisions related to the configuration of a supply chain networks involve the manufacturing stages and can be divided into primary manufacturing for active ingredients and secondary manufacturing for formulations and packaging, storage facilities, secondary sites, warehouses, product market areas, distribution networks, and vehicle routing optimization.

Although there are a considerable number of studies of the development of models for the supply chain network design, only a small proportion of these works is related to the pharmaceutical sector.

One of the first studies of network design for the pharmaceutical industry was developed by Rotstein et al. [20]. In this paper, the authors develop an optimization model for product development, introduction strategy, capacity strategy, and investment strategy. In order to solve the problem, the authors use a two-stage stochastic programming method; the first stage includes the decisions that must be made immediately, while the second stage includes decisions about capacities. In the second stage, a large number of scenarios are used for the different combinations of outcomes of the independent clinical trials for different drugs. A similar approximation to this problem was developed in 2001 [21]. In this paper, an optimization-based approach is developed for selecting product development, introduction strategy, and capacity planning. The problem is formulated in terms of a mixed-integer linear programming model, taking into account the global trading structures and the particular features of manufacturing active pharmaceutical ingredients. Extensions of this work were presented in 2003 [22] and 2004 [23]. In the first approximation, the authors develop a multiscenario mixed-integer programming method and present a hierarchical algorithm for reduction of the computational time. In the second approximation, they propose a systematic mathematical programming approach for long-term multisite capacity planning under conditions of uncertainty. The problem is formulated as a two-stage, multiscenario, mixed-integer linear programming model and can determine both the product portfolio and the capacity planning. A hierarchical algorithm is proposed for reducing the computational time.

Gatica et al. [24] develop a model that considers a group of pharmaceutical plants which plan to manufacture a set of various products. Products are divided into two types: those for which demand can be considered deterministic, since they are already in the market and forecasting can be derived reasonably well and those for which demand is stochastic. The authors develop a mathematical optimization model to determine the final product portfolio, capacity 
TABLE 1: Quantitative models of supply chain network design.

\begin{tabular}{|c|c|c|c|c|c|}
\hline Author & $\begin{array}{c}\text { Source of } \\
\text { uncertainty }\end{array}$ & $\begin{array}{l}\text { Type of } \\
\text { demand }\end{array}$ & $\begin{array}{c}\text { Number of } \\
\text { medicines }\end{array}$ & Supply chain components & Methodology \\
\hline Rotstein et al. (1999) & $\begin{array}{c}\text { Consumption of } \\
\text { manufacturing } \\
\text { resources }\end{array}$ & Deterministic & 8 & Manufacture & Stochastic programming \\
\hline Papageorgiou et al. (2001) & & Deterministic & 7 & Manufacture & Optimization \\
\hline Levis and Papageorgiou (2003) & & Deterministic & 7 & Manufacture & $\begin{array}{c}\text { Optimization } \\
\text { Heuristic } \\
\end{array}$ \\
\hline Levis and Papageorgiou (2004) & $\begin{array}{c}\text { Clinical trials } \\
\text { outcomes }\end{array}$ & Deterministic & 7 & Manufacture & $\begin{array}{c}\text { Optimization } \\
\text { heuristic }\end{array}$ \\
\hline Gatica et al. (2003a) & Demand & $\begin{array}{c}\text { Deterministic } \\
\text { stochastic }\end{array}$ & 12 & Manufacture & Optimization \\
\hline Gatica et al. (2003b) & Demand & $\begin{array}{c}\text { Deterministic } \\
\text { and } \\
\text { stochastic }\end{array}$ & 12 & Manufacture & Heuristic \\
\hline Chambers et al. (2009) & $\begin{array}{l}\text { Demand and } \\
\text { technical } \\
\text { aspects }\end{array}$ & Stochastic & 5 & Manufacture & $\begin{array}{l}\text { Stochastic dynamic } \\
\text { optimization }\end{array}$ \\
\hline Susarla and Karimi (2012) & & Deterministic & 8 & $\begin{array}{c}\text { Manufacture } \\
\text { Warehouse } \\
\text { Waste treatment plant }\end{array}$ & Optimization \\
\hline Mousazadeh et al. (2015) & Demand costs & Stochastic & 1 & $\begin{array}{c}\text { Manufacture } \\
\text { distribution center }\end{array}$ & $\begin{array}{l}\text { Multiobjective } \\
\text { optimization }\end{array}$ \\
\hline
\end{tabular}

planning, optimal production planning, and the sales and inventory planning profiles. Due to the large number of products and scenarios, this implementation is only useful in small instances. In order to solve this problem, the same authors develop an aggregation approach [25]. The results of the proposed approach show that a substantial improvement in computational time is achieved by using the aggregation scheme.

Another model focusing on the capacity planning for product introduction has been proposed [26]. The focus of the article is not only on demand uncertainty but also on technical uncertainty. Specifically, these authors evaluate the use of process flexibility in risky new product development in the pharmaceutical industry. The proposed model is solved using stochastic dynamic optimization, with the result that it can be used to determine the optimal capacity and allocation decisions for a flexible facility.

A complete model for multisite, multiechelon, multiperiod enterprise planning and global network of a pharmaceutical company is developed by [27]. The model integrates procurement, production planning, and distribution with the effects of international tax differentials, inventory holding costs, and other real-life factors. The proposed model is evaluated over two real sets of data although this does not include stochastic uncertainty.

For the case of the design of a pharmaceutical supply chain network under fuzzy uncertainty, Mousazadeh et al. [28] develop a biobjective mixed-integer linear programming model. Using this solution to the mathematical model the opening of manufacturing and distribution centers and the flows over the logistic chain can be determined. The parameters involving uncertainty which are included in this model are demand, unit manufacturing costs, unit transportation and transshipment costs, and safety stock levels. In order to test the proposed model, real data is used, collected from a national organization. Finally multiobjective decisionmaking techniques are used and tested on the data.

It can be concluded that although this is a very important topic due to its impact on the community, applications in the pharmaceutical sector are focused only on the manufacturing process, despite the design and configuration of a new pharmaceutical supply chain network requiring specific elements that belong to this sector.

In the majority of articles, the type of demand used is deterministic and is not used for a large variety of medicines. Since most of the papers use a deterministic approach, the trends used in the quantitative models are classical linear programing models and the development of heuristics. Future research in this topic may include the configuration of real pharmaceutical supply chains including uncertainty aspects of the configurations. We describe the quantitative models in pharmaceutical supply chain network design and summarize these in Table 1.

4.2. Inventory Problems. This section identifies problems related to inventory control in pharmacies and hospitals. 
Inventory models are one of the most studied problems in the literature, although inventory management in the pharmaceutical supply chain has been given little attention. Almarsdóttir and Traulsen [29] describe reasons for pharmaceuticals and hospitals deserving a high level of consideration in terms of inventory control for medicines and other kinds of consumer products. Certain specific features are studied, for instance, the perishability of products, lead times, and constraints on capacity among others.

A first approach to inventory management in a hospital was developed by [30]. This paper presents a stochastic and periodic review model in which the objectives used are formulated in terms of stock-out and budget. The model contemplates the use of three kinds of medicines, and results are analyzed with a sensitive analysis.

Little and Coughlan (2008) develop a constraint-based model for determining stock levels for all products at a storage location with space constraints, which takes into account the criticality of medicines. The decision variables are related to the service level, the frequency of delivery, and the amount to order up. The objectives tested are the maximization of the minimum service level and the maximization of the average service level. The models are tested using 110 different medicines [9]. This model is an extension of a previous article presented by [31].

One of the first extended models was proposed by Dellaert and Van De Poel [32]. Their proposed model is an extension of the $(R, s, S)$ model. It is denoted as the $(R$, $s, c, S$ ) model and is obtained using the EOQ model. The proposed model considers stochastic demand and is tested using a planning horizon of 100 time periods and 1544 items. After implementation in the hospital and an evaluation, it was determined that the total costs are reduced.

Another approximation of an inventory model has been developed by Kelle et al. [33]. These authors formulated two exact models for decisions at an operational level. The first is an $(s, S)$ model with space constraints; the parameters are assumed to be random variables and shortages are allowed. The second model is formulated in terms of optimal allocation based on ordering and holding costs, which are considered to be a service level constraint rather than a shortage. Through the use of this model it is demonstrated that the total cost of pharmaceutical inventory can be reduced by up to $80 \%$. The algorithms are coded in VBA.

An approximation of inventory control via simulation was developed by Vila-Parrish et al. [34]. The model involves two stages; the first consists of the development of a Markov decision process to represent drug demand as a function of the patient condition, allowing the determination of the appropriate drug inventory levels. The second phase consists of the use of simulation to evaluate the inventory policies characterized in the first phase. In this simulation model, the lead times and fixed production costs are not taken into account. In contrast to this approximation, Wu et al. develop a simulation model using system dynamics [35]. In this paper, the demand is approximated as a normal distribution and a safety stock is used. The scenarios used in the simulation show that shortages can be reduced. Another approximation using system dynamics was developed by Wang et al. [36]. Using the results of their simulation, these authors develop a dynamic drum-buffer-rope replenishment model. A Powell search algorithm is used to determine buffer sizes and inventory quantities. The model is tested on real data, demonstrating that the model can find the optimal replenishment timing and quantity, minimizing the total cost and with no stock-out occurrence.

There is an approximation to the pharmaceutical inventory models using RFID [37]. In this article, the authors demonstrate that continuous review is superior to periodic review whenever accurate real-time information is available with no additional cost. The proposed model takes into account only one product, and the demand is modeled as a continuous stochastic process with stationary and independent increments. The lead time is assumed to be deterministic and a constant number and shortage are backordered. While this model does not consider the economic effect of the use of RFIDs, [38] develops some approximations of the real costs of the use of RFIDs in the pharmaceutical supply chain.

While most of the objective functions consider the minimization of total costs, [39] considers the maximization of the total net profit. The problem is formulated by these authors as a mixed-integer linear programming model with a hybrid time representation. The model considers the use of the VMI strategy with three months of planning horizon and 15 products.

Guerrero et al. (2013) propose a model for a multiproduct multiechelon process [40]. The demand is assumed to be stochastic, Poisson-distributed, and independent between products. The problem is formulated as a Markov chain with the objective of minimizing the stock-on-hand value. The model determines both the reorder level and the order-upto level. A heuristic algorithm is proposed to reduce the computational time.

A mathematical model using two forms of stochastic data has been developed by [41]. This is the only article that assumes a stochastic bill of materials for the procedures in an operating room; in addition, a stochastic demand is assumed. The authors develop a mathematical model using stochastic uncertainty and test this using real data.

Two exact models for lost sales and limited storage capacity have been developed by [42]. In the capacity model, the service level is maximized subject to a capacity constraint; in the service model, the capacity required is minimized subject to a service level constraint. Moreover, the authors develop a simple heuristic for the capacity model in which the reorder levels and order quantities are fixed.

The results of this analysis are presented in Table 2. It is important to mention that the majority of the methods proposed are useful only in small instances, despite the fact that, in real cases, hospitals, clinics, and pharmacies work with an extremely large number of medicines.

4.3. Optimization of the Pharmaceutical Supply Chain Network. An online procurement system has been developed by Kim [43]. In this model, a supply chain network is considered, 


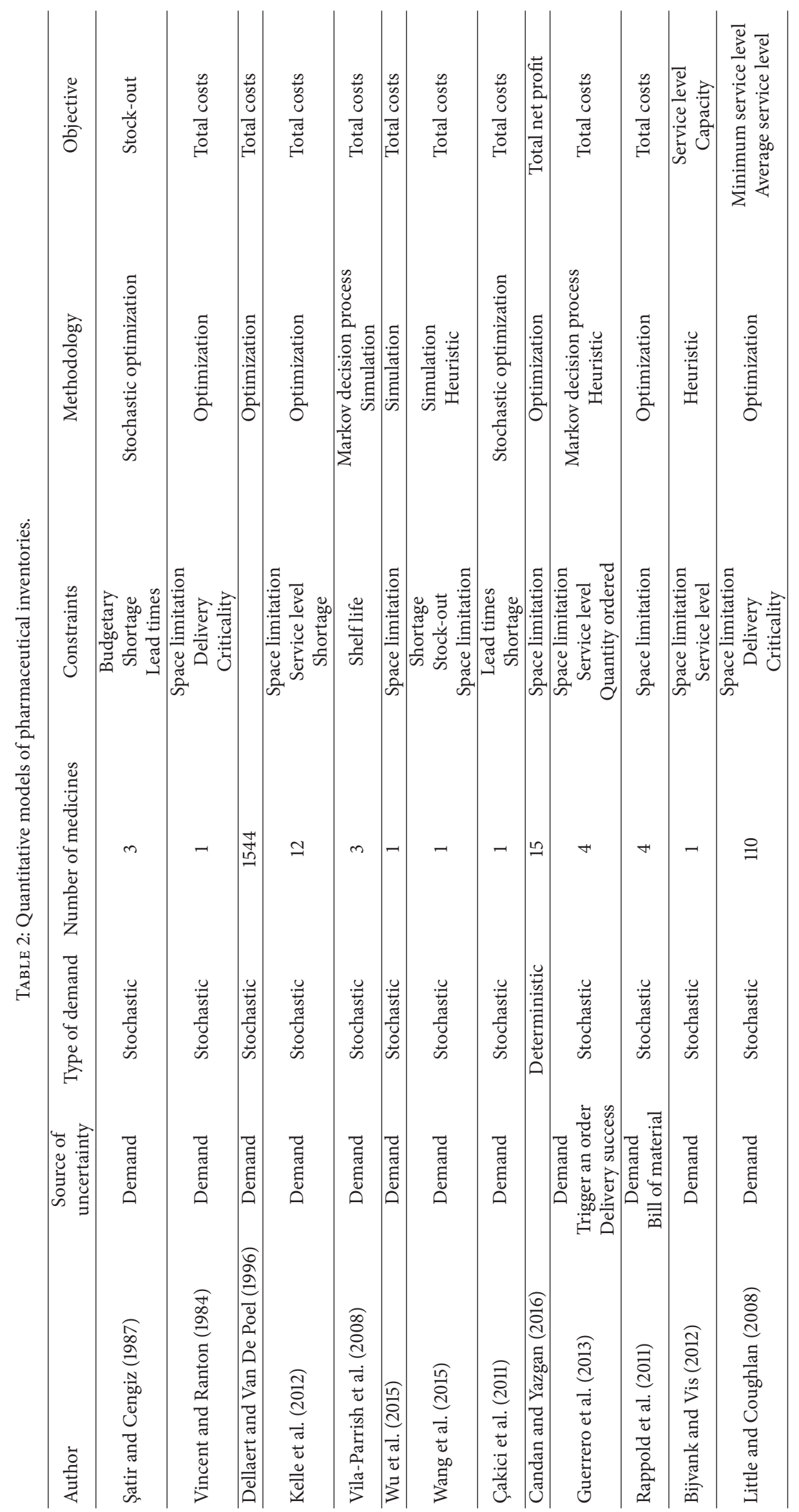


involving a group of pharmaceutical companies, wholesalers, and hospitals. Due to an online system implementation, realtime information is provided for optimizing the inventory control of pharmaceuticals. Through the use of the proposed model, the total costs can be reduced and a vendor management system strategy can be adopted which involves sharing information with wholesalers.

Baboli et al. [44] propose two models for centralized and decentralized supply chains. The basic model consists of one warehouse and one retailer, and the products are assumed to have a deterministic demand which corresponds to items with a stable demand and high turnover rate. The centralized model is considered to be a single organization in which the warehouse and the retailer belong to the same organization, while in the decentralized model the warehouse and the retailer are treated as external companies. Other works deal with the problem of optimization of a supply chain in a centralized model, such as that proposed by [45]; in this study, a system dynamic simulation model is developed using a careful analysis which demonstrates that logistics outsourcing is often the most economical choice. Nevertheless, the proposed model is only applicable to small instances due to the complexity of the interactions within the chain. While this model is a mathematical approximation, Hassan et al. [46] have put forward an analysis based on the best practices for supply chain management; these authors generate eight possible scenarios and use a multicriteria decision-making model to evaluate these.

Uthayakumar and Priyan [47] develop a model that integrates continuous review with production and distribution. The model considers a set of products, variable lead times, payment delays, constraints of space availability, and customer service level. The proposed mathematical model takes into account a random demand, a deterministic expiration date, and a random lead time that is assumed to be a normal random variable; the production rate of the medicines is also considered. The model is formulated as a two-echelon supply chain in order to identify the optimal inventory lot size by minimizing the integrated expected total cost. A Lagrangian relaxation is used to solve the proposed model. The same authors develop a model which involves a fuzzy stochastic environment [48]. The total cost of inventory management is considered as a fuzzy variable in a multiechelon, multiproduct, multiconstraint inventory based on the distance method. Another model that considers stochastic uncertainty has been proposed by Zhao et al. [49]. The demand is assumed to be stochastic; information available for the model includes a set of prices from the manufacturers, the production rate, and the initial inventory. The model is divided into the optimal policy for the manufacturer and that for the distributor and proves that the solutions enhance the profits in the echelons of the chain. Finally, a heuristic to estimate the Pareto-improving fee range is proposed.

Although in the majority of the articles the authors describe a distribution network and its optimization, Nicholson et al. propose a model to evaluate the outsourcing of noncritical inventory items [50]. The proposed model includes a comparison of a three-echelon distribution network versus an outsourced two-echelon distribution network. The model proposed for the three-echelon distribution network is an extension of the work of $[51,52]$. The proposed model takes into account only a single product, which has a stochastic demand. Two heuristics are proposed for testing the proposed model.

Although in most of the articles the authors develop models considering uncertainty, Balcázar-Camacho et al. [53] and Stecca et al. [54] develop a linear programming model for a distribution network. The model proposed considers a multiechelon distribution system in which the objective function involves the minimization of the total costs. Although the mathematical models proposed by these authors consider some elements concerning the real composition of networks, the instances used for testing the model are small and do not correspond to the size of a supply chain network.

A real case of a pharmaceutical chain in India is studied by Dutta et al. [55]. The authors describe a multiperiodbased decision support system for planning within the pharmaceutical process. The model includes manufacturers and warehouses, decisions on materials, and production activities. A mathematical linear model is proposed using seven types of medicines.

While discrete simulation is used in the majority of articles, Jetly et al. propose a multiagent simulation model for the pharmaceutical supply chain [56]. The model is used to prove that the norms of a specific industry can be used to represent a specific industry capable of tracking its evolution. The model is tested with three kinds of medicines and includes 30 manufacturers, 60 suppliers, and 60 distributors. The lifecycle is also modeled.

A different type of study was performed by Eberle et al. [57]. This study consisted of implementing a Monte Carlo simulation to reduce the lead times of the production processes. The main medicines involved in the simulation model are both parenteral and injectable medicines. The results of the simulation are evaluated with a "what if" technique to assess the effect of investments in resource allocation and process improvements.

Masoumi et al. [58] propose a network oligopoly model. This model uses arc multipliers for supply chains using inequality theory. The model takes into account the perishability of pharmaceuticals and the objective is to maximize the product flows.

Hansen and Grunow [59] consider the problem of supporting planning operations before market launch in the pharmaceutical supply chain. A two-stage stochastic model to support the market launch preparation is developed in this study.

An algorithm for integrating decisions on inventory and purchases has been developed by Rego et al. [60]. The model estimates the number, size, and composition of purchasing groups for a set of hospitals with the objective of minimizing the supply chain costs. The proposed algorithm is based on the variable neighborhood search within a Tabu metaheuristic search. The proposed algorithm is tested with two items and a set of 15 providers. 
A coordination problem between plants in pharmaceutical supply networks is studied by Grunow et al. [61]. These authors propose several aggregation schemes and a novel mixed-integer linear programming model formulation based on a continuous representation of time. A heuristic approach is developed in order to solve real-life problem instances.

An enormous number of studies on reverse logistics can be found in the literature; however, studies of reverse logistics within the pharmaceutical supply chain have not yet been highly developed by researchers.

Reverse logistics in the pharmaceutical context consist of the collection of the unwanted or unused medications from pharmacies or hospitals. The objectives of reverse logistics are diverse and include the minimization of fees and penalties paid to governments by industry, maximization of unwanted products collected, maximization of individual profit, minimization of collection costs, and minimization of waste, among others.

A real case within the pharmaceutical industry is developed by [62]. At the planning level, an aggregation description is proposed for the supply chain operational model. A master representation is defined to support supply chain resources, and a mathematical formulation is then proposed for optimal supply chain planning. Once the results of the supply chain planning are obtained, the scheduling model is formulated using a mathematical model.

As described above, few works can be found on reverse logistics applied within the pharmaceutical sector. Weraikat et al. [63] propose a linear programming model with a Lagrangian relaxation including a negotiation with 3PL providers. Shih and Lin have presented a multicriteria optimization approach to minimize the total cost of collection system planning for medical waste [64]; a similar work is presented by Weraikat et al. [65] in which a nonlinear mathematical programming model is developed. Xie and Breen [66] designed a green pharmaceutical supply chain model to reduce pharmaceutical waste $[65,66]$. Although other studies of reverse logistics include several other features, quantitative models are not included.

Most of the articles in this review include uncertainty in demand, which is modeled as a stochastic function. Nevertheless, real approximations of hospital problems are not developed in the literature because the number of items involved is far too high for efficient operation. Future research on this topic should include coordination between various medicines and should develop powerful algorithms to handle the very large number of items.

The final analysis of this work is presented in Table 3. A conclusion can be drawn that most of the articles regarding optimization of the supply chain models take into account only a small number of medicines, thus reducing the complexity of the interactions between the echelons and the medicines.

\section{Conclusions}

In this paper we present a literature review of quantitative models of the pharmaceutical supply chain. We identify three classification categories in terms of strategic, tactical, and operational decisions. The source of uncertainty used in the models is presented in this review, with the finding that the majority of articles use a stochastic form of uncertainty in some of the echelons of the chain. We found in the taxonomy proposed that $52 \%$ of the articles correspond to network design, $28 \%$ correspond to inventory problems, and $20 \%$ correspond to supply chain optimization models.

Several deterministic models are presented, but in the majority of cases the use of techniques is developed under uncertainty. Most of the articles involve stochastic approximations, and only a few uses an alternative approximation of uncertainty, for example, fuzzy logic and robust optimization, among others. In network design $56 \%$ of the articles use the demand as deterministic and $22 \%$ as stochastic and $22 \%$ of the articles used both types of demand while in inventory models $92 \%$ of the articles use the demand as stochastic and $8 \%$ as deterministic. In supply chain optimization $52 \%$ of the articles use the demand as deterministic and $48 \%$ as stochastic.

Even when the studies of quantitative models combine different kinds of techniques, we conclude in this review that there is a lack of the use of combined techniques that will allow researchers to approximate the operation of a pharmaceutical supply chain in a realistic way. Some of these techniques involve optimization via simulation, simulation-optimization, stochastic network modeling, and fuzzy optimization. For network design the most common technique used is classic optimization with $33 \%$ of the cases, while combination between classic optimization and heuristics was used in $22 \%$ of the cases and each of stochastic optimization, heuristics, stochastic dynamic optimization, and multiobjective optimization was used with $11 \%$ of the cases. On inventory models the most common technique used is optimization with $46 \%$ of the cases while stochastic optimization is used in $15 \%$ of the cases, also Markov decision process with simulation, simulation, simulation with heuristic, Markov decision process with heuristic, and heuristics are used with $8 \%$, respectively. In supply chain optimization the most common technique used is classic optimization with $46 \%$ of the cases; also Lagrangian relaxation, heuristics, and simulation are used with $8 \%$ of the cases, respectively; also optimization with simulation, multicriteria decision-making, inequality theory, stochastic optimization, metaheuristics, and multicriteria optimization are used with $4 \%$ of the cases, respectively.

Finally, judging from the number of publications in this area, pharmaceutical supply chain is a significant topic with important real-world applications; however, despite some recent developments, there remain few works on this subject.

\section{Conflicts of Interest}

The authors declare that there are no conflicts of interest regarding the publication of this paper. 


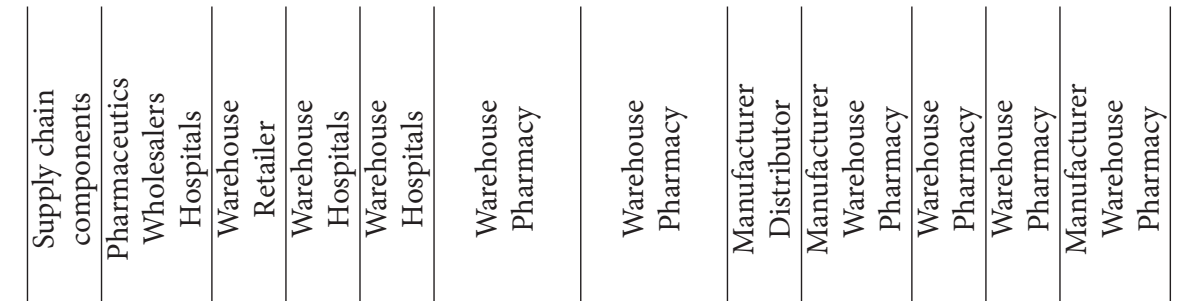

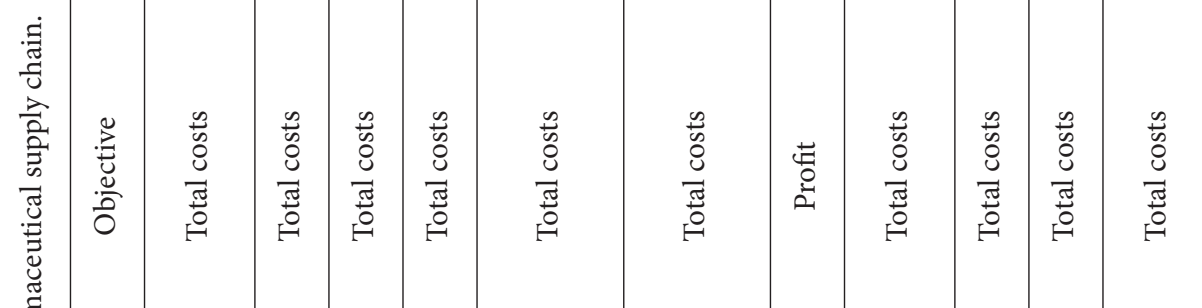

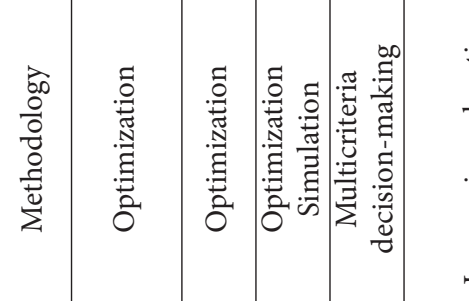

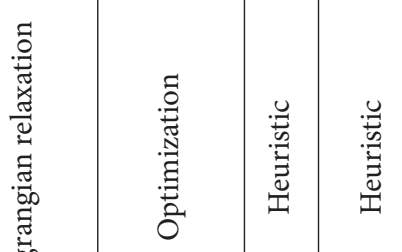

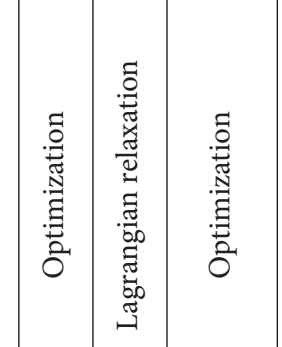

듬

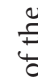

(1)

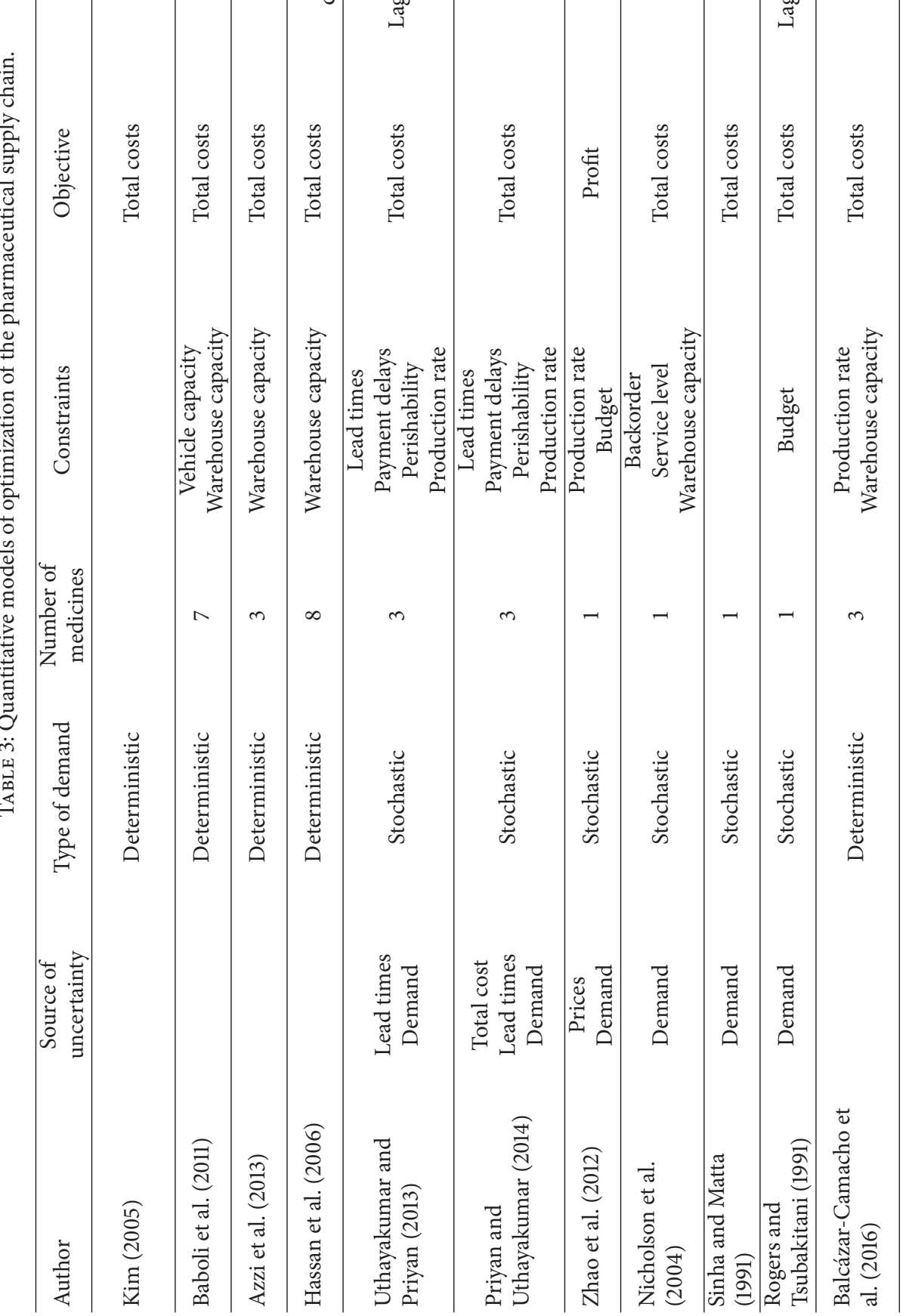




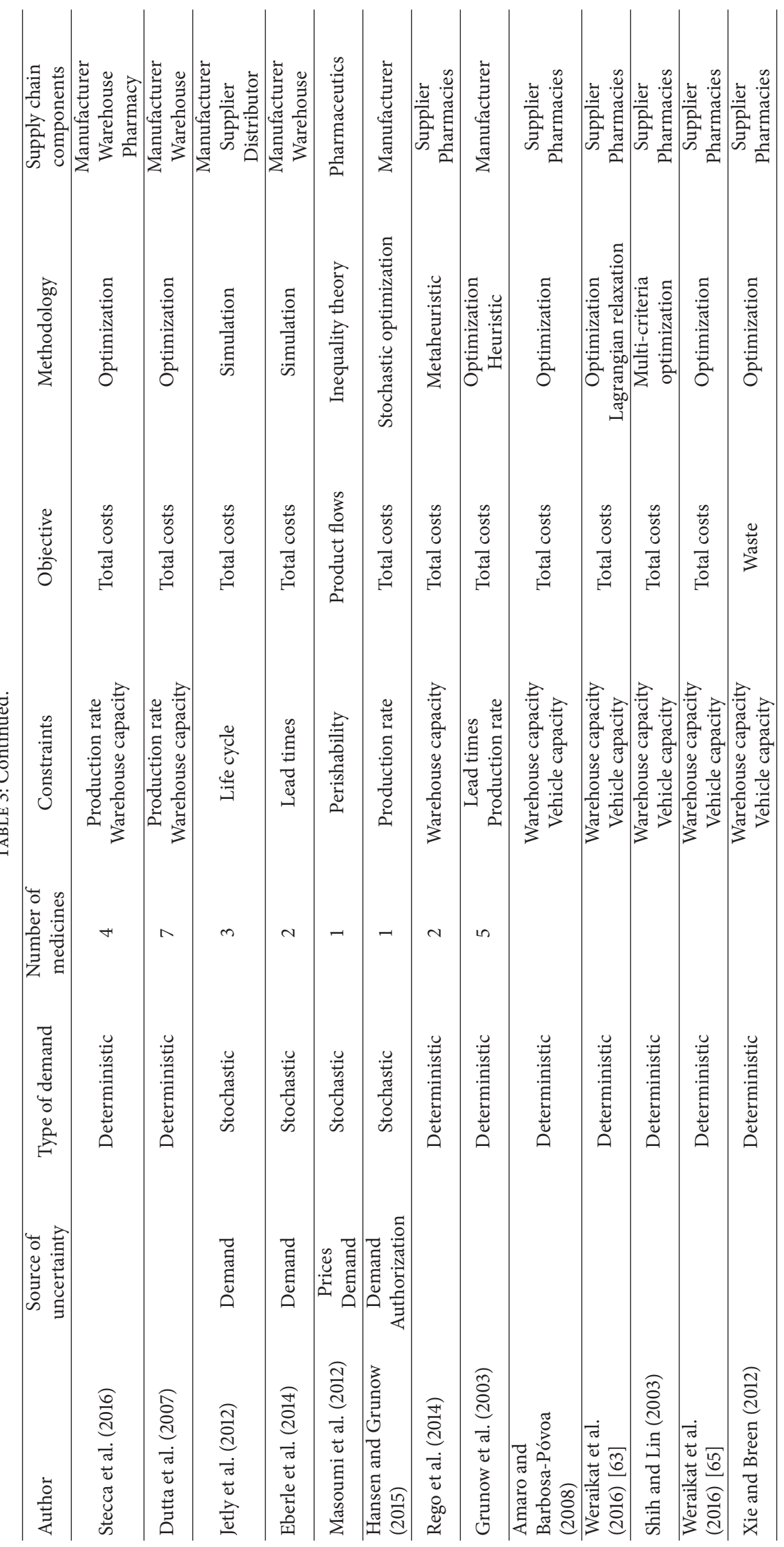




\section{References}

[1] S. Ahmadiani and S. Nikfar, "Challenges of access to medicine and the responsibility of pharmaceutical companies: a legal perspective," DARU Journal of Pharmaceutical Sciences, vol. 24, article 13, 2016.

[2] J. Rankin, J. D. Quickand, and S. Muziki, Operational Principles for Good Pharmaceutical Procurement, Geneva, Switzerland, 1999.

[3] L. Burns, The Health Care Value Chain Producers, Purchasers and Providers, Wharton School Colleagues, 2002.

[4] S. H. Chung and C. Kwon, "Integrated supply chain management for perishable products: Dynamics and oligopolistic competition perspectives with application to pharmaceuticals," International Journal of Production Economics, vol. 179, pp. 117129, 2016.

[5] R. T. Sousa, S. Liu, L. G. Papageorgiou, and N. Shah, "Global supply chain planning for pharmaceuticals," Chemical Engineering Research and Design, vol. 89, no. 11, pp. 2396-2409, 2011.

[6] R. B. Handfield and E. L. Nichols, Introduction to Supply Chain Management, Prentice Hall, New Jersey, NJ, USA, 1999.

[7] S. A. Narayana, R. Kumar Pati, and P. Vrat, "Managerial research on the pharmaceutical supply chain-a critical review and some insights for future directions," Journal of Purchasing and Supply Management, vol. 20, no. 1, pp. 18-40, 2014.

[8] WHO, "The World Health Report Health System Financing: the path to universal coverage," Tech. Rep., World Health Organization (WHO), 2010.

[9] J. Little and B. Coughlan, "Optimal inventory policy within hospital space constraints," Health Care Management Science, vol. 11, no. 2, pp. 177-183, 2008.

[10] O. Aptel and H. Pourjalali, "Improving activities and decreasing costs of logistics in hospitals: a comparison of U.S. and French hospitals," The International Journal of Accounting, vol. 36, no. 1, pp. 65-90, 2001.

[11] I. Z. Karaesmen, A. Scheller-Wolf, and B. Deniz, "Planning production and inventories in the extended enterprise," in Managing Perishable and Aging Inventories: Review and Future Research Directions, pp. 393-436, Springer, 2011.

[12] J. M. Laínez, E. Schaefer, and G. V. Reklaitis, "Challenges and opportunities in enterprise-wide optimization in the pharmaceutical industry," Computers \& Chemical Engineering, vol. 47, pp. 19-28, 2012.

[13] I.-W. G. Kwon, S.-H. Kim, and D. G. Martin, "Healthcare supply chain management; strategic areas for quality and financial improvement," Technological Forecasting \& Social Change, vol. 113, pp. 422-428, 2016.

[14] S. A. Narayana, R. K. Pati, and P. Vrat, "Research on management issues in the pharmaceutical industry: a literature review," International Journal of Pharmaceutical and Healthcare Marketing, vol. 6, no. 4, pp. 351-375, 2012.

[15] N. Privett and D. Gonsalvez, "The top ten global health supply chain issues: perspectives from the field," Operations Research for Health Care, vol. 3, no. 4, pp. 226-230, 2014.

[16] C. Alverson, "Beyond purchasing-managing hospital inventory," in Pharmacy Management, Advanstar Communications Inc, 2003.

[17] N. Shah, "Pharmaceutical supply chains: key issues and strategies for optimisation," Computers \& Chemical Engineering, vol. 28, no. 6-7, pp. 929-941, 2004.
[18] J. Volland, A. Fügener, J. Schoenfelder, and J. O. Brunner, "Material logistics in hospitals: a literature review," OMEGA, vol. 69, pp. 82-101, 2017.

[19] R. H. Ballou, "Business logistics: importance and some research opportunities," Gestão \& Produção, vol. 4, no. 2, pp. 117-129, 1997.

[20] G. E. Rotstein, L. G. Papageorgiou, N. Shah, D. C. Murphy, and R. Mustafa, "A product portfolio approach in the pharmaceutical industry," Computers \& Chemical Engineering, vol. 23, supplement 1, pp. S883-S886, 1999.

[21] L. G. Papageorgiou, G. E. Rotstein, and N. Shah, "Strategic supply chain optimization for the pharmaceutical industries," Industrial \& Engineering Chemistry Research, vol. 40, no. 1, pp. 275-286, 2001.

[22] A. A. Levis and L. G. Papageorgiou, "Multi-site capacity planning for the pharmaceutical industry using mathematical programming," Computer Aided Chemical Engineering, vol. 14, pp. 1097-1102, 2003.

[23] A. A. Levis and L. G. Papageorgiou, "A hierarchical solution approach for multi-site capacity planning under uncertainty in the pharmaceutical industry," Computers \& Chemical Engineering, vol. 28, no. 5, pp. 707-725, 2004.

[24] G. Gatica, L. G. Papageorgiou, and N. Shah, "Capacity planning under uncertainty for the pharmaceutical industry," Chemical Engineering Research and Design, vol. 81, no. 6, pp. 665-678, 2003.

[25] G. Gatica, L. Papageorgiou, and N. Shah, "An aggregation approach for capacity planning under uncertainty for the pharmaceutical industry," in Proceedings of the FOCAPO 2003 Conference, Florida, Fla, USA, 2003.

[26] C. G. Chambers, E. M. Snir, and A. Ata, "The use of flexible manufacturing capacity in pharmaceutical product introductions," Decision Sciences, vol. 40, no. 2, pp. 243-268, 2009.

[27] N. Susarla and I. A. Karimi, "Integrated supply chain planning for multinational pharmaceutical enterprises," Computers \& Chemical Engineering, vol. 42, pp. 168-177, 2012.

[28] M. Mousazadeh, S. A. Torabi, and B. Zahiri, "A robust possibilistic programming approach for pharmaceutical supply chain network design," Computers \& Chemical Engineering, vol. 82, pp. 115-128, 2015.

[29] A. B. Almarsdóttir and J. M. Traulsen, "Cost-containment as part of pharmaceutical policy," Pharmacy world and science, vol. 27, no. 3, pp. 144-148, 2005.

[30] A. Şatir and D. Cengiz, "Medicinal inventory control in a university health centre," Journal of the Operational Research Society, vol. 38, no. 5, pp. 387-395, 1987.

[31] V. Vincent and M. Ranton, "Hospital pharmacy inventory management: economic order quantity model with space limitation," Hospital Materiel Management Quarterly, vol. 5, no. 3, pp. 82-86, 1984.

[32] N. Dellaert and E. Van De Poel, "Global inventory control in an academic hospital," International Journal of Production Economics, vol. 46-47, pp. 277-284, 1996.

[33] P. Kelle, J. Woosley, and H. Schneider, "Pharmaceutical supply chain specifics and inventory solutions for a hospital case," Operations Research for Health Care, vol. 1, no. 2-3, pp. 54-63, 2012.

[34] A. R. Vila-Parrish, J. S. Ivy, and R. E. King, "A simulation-based approach for inventory modeling of perishable pharmaceuticals," in Proceedings of the 2008 Winter Simulation Conference, WSC 2008, pp. 1532-1538, Miami, Fla, USA, December 2008. 
[35] D. Wu, M. D. Rossetti, and J. E. Tepper, "Possibility of inventory pooling in China's public hospital and appraisal about its performance," Applied Mathematical Modelling, vol. 39, no. 2324, pp. 7277-7290, 2015.

[36] L.-C. Wang, C.-Y. Cheng, Y.-T. Tseng, and Y.-F. Liu, "Demandpull replenishment model for hospital inventory management: a dynamic buffer-adjustment approach," International Journal of Production Research, vol. 53, no. 24, pp. 7533-7546, 2015.

[37] Ö. E. Çakici, H. Groenevelt, and A. Seidmann, "Using RFID for the management of pharmaceutical inventory-system optimization and shrinkage control," Decision Support Systems, vol. 51, no. 4, pp. 842-852, 2011.

[38] M.-P. Schapranow, J. Müller, A. Zeier, and H. Plattner, "Costs of authentic pharmaceuticals: research on qualitative and quantitative aspects of enabling anti-counterfeiting in RFID-aided supply chains," Personal and Ubiquitous Computing, vol. 16, no. 3, pp. 271-289, 2012.

[39] G. Candan and H. R. Yazgan, "A novel approach for inventory problem in the pharmaceutical supply chain," DARU Journal of Pharmaceutical Sciences, vol. 24, article 4, 2016.

[40] W. J. Guerrero, T. G. Yeung, and C. Guéret, "Joint-optimization of inventory policies on a multi-product multi-echelon pharmaceutical system with batching and ordering constraints," European Journal of Operational Research, vol. 231, no. 1, pp. 98108, 2013.

[41] J. Rappold, B. Van Roo, C. Di Martinelly, and F. Riane, "An inventory optimization model to support operating room schedules," Supply Chain Forum: An International Journal, vol. 12, no. 1, pp. 56-69, 2011.

[42] M. Bijvank and I. F. A. Vis, "Inventory control for point-ofuse locations in hospitals," Journal of the Operational Research Society, vol. 63, no. 4, pp. 497-510, 2012.

[43] D. Kim, "An integrated supply chain management system: a case study in healthcare sector," in E-Commerce and Web Technologies, vol. 3590 of Lecture Notes in Computer Science, pp. 218-227, Springer, Berlin, GErmany, 2005.

[44] A. Baboli, J. Fondrevelle, R. Tavakkoli-Moghaddam, and A. Mehrabi, "A replenishment policy based on joint optimization in a downstream pharmaceutical supply chain: centralized vs. decentralized replenishment," The International Journal of Advanced Manufacturing Technology, vol. 57, no. 1-4, pp. 367378, 2011.

[45] A. Azzi, A. Persona, F. Sgarbossa, and M. Bonin, "Drug inventory management and distribution: outsourcing logistics to third-party providers," Strategic Outsourcing: An International Journal, vol. 6, no. 1, pp. 48-64, 2013.

[46] T. Hassan, A. Baboli, A. Guinet, G. Leboucher, and M. Brandon, "Re-organizing the pharmaceutical supply chain downstream: implementation a new pharmacy," IFAC Proceedings Volumes, vol. 39, no. 3, pp. 727-732, 2006.

[47] R. Uthayakumar and S. Priyan, "Pharmaceutical supply chain and inventory management strategies: optimization for a pharmaceutical company and a hospital," Operations Research for Health Care, vol. 2, no. 3, pp. 52-64, 2013.

[48] S. Priyan and R. Uthayakumar, "Optimal inventory management strategies for pharmaceutical company and hospital supply chain in a fuzzy-stochastic environment," Operations Research for Health Care, vol. 3, no. 4, pp. 177-190, 2014.

[49] H. Zhao, C. Xiong, S. Gavirneni, and A. Fein, "Fee-forservice contracts in pharmaceutical distribution supply chains: design, analysis, and management," Manufacturing and Service Operations Management, vol. 14, no. 4, pp. 685-699, 2012.

[50] L. Nicholson, A. J. Vakharia, and S. Selcuk Erenguc, "Outsourcing inventory management decisions in healthcare: models and application," European Journal of Operational Research, vol. 154, no. 1, pp. 271-290, 2004.

[51] D. Sinha and K. F. Matta, "Multiechelon (R, S) Inventory Model," Decision Sciences, vol. 22, no. 3, pp. 484-499, 1991.

[52] D. F. Rogers and S. Tsubakitani, "Inventory positioning/ partitioning for backorders optimization for a class of multiechelon inventory problems," Decision Sciences, vol. 22, no. 3, pp. 536-558, 1991.

[53] D. A. Balcázar-Camacho, C. A. López-Bello, and W. AdarmeJaimes, "Strategic guidelines for supply chain coordination in healthcare and a mathematical model as a proposed mechanism for the measurement of coordination effects," DYNA, vol. 83, no. 197, pp. 204-212, 2016.

[54] G. Stecca, I. Baffo, and T. Kaihara, "Design and operation of strategic inventory control system for drug delivery in healthcare industry," IFAC-PapersOnLine, vol. 49, no. 12, pp. 904-909, 2016.

[55] G. Dutta, R. Fourer, A. Majumdar, and D. Dutta, "An optimization-based decision support system for strategic planning in a process industry: the case of a pharmaceutical company in India," International Journal of Production Economics, vol. 106, no. 1, pp. 92-103, 2007.

[56] G. Jetly, C. L. Rossetti, and R. Handfield, "A multi-agent simulation of the pharmaceutical supply chain," Journal of Simulation, vol. 6, no. 4, pp. 215-226, 2012.

[57] L. G. Eberle, H. Sugiyama, and R. Schmidt, "Improving lead time of pharmaceutical production processes using Monte Carlo simulation," Computers \& Chemical Engineering, vol. 68, pp. 255-263, 2014.

[58] A. H. Masoumi, M. Yu, and A. Nagurney, "A supply chain generalized network oligopoly model for pharmaceuticals under brand differentiation and perishability," Transportation Research Part E: Logistics and Transportation Review, vol. 48, no. 4, pp. 762-780, 2012.

[59] K. R. N. Hansen and M. Grunow, "Planning operations before market launch for balancing time-to-market and risks in pharmaceutical supply chains," International Journal of Production Economics, vol. 161, pp. 129-139, 2015.

[60] N. Rego, J. Claro, and J. Pinho de Sousa, "A hybrid approach for integrated healthcare cooperative purchasing and supply chain configuration," Health Care Management Science, vol. 17, no. 4, pp. 303-320, 2014.

[61] M. Grunow, H.-O. Günther, and G. Yang, "Plant co-ordination in pharmaceutics supply networks," OR Spectrum, vol. 25, no. 1 , pp. 109-141, 2003.

[62] A. C. S. Amaro and A. P. F. D. Barbosa-Póvoa, "Planning and scheduling of industrial supply chains with reverse flows: a real pharmaceutical case study," Computers \& Chemical Engineering, vol. 32, no. 11, pp. 2606-2625, 2008.

[63] D. Weraikat, M. K. Zanjani, and N. Lehoux, "Coordinating a green reverse supply chain in pharmaceutical sector by negotiation," Computers \& Industrial Engineering, vol. 93, pp. 67-77, 2016.

[64] L.-H. Shih and Y.-T. Lin, "Multicriteria optimization for infectious medical waste collection system planning," Practice Periodical of Hazardous, Toxic, and Radioactive Waste Management, vol. 7, no. 2, pp. 78-85, 2003. 
[65] D. Weraikat, M. K. Zanjani, and N. Lehoux, "Two-echelon pharmaceutical reverse supply chain coordination with customers incentives,' International Journal of Production Economics, vol. 176, pp. 41-52, 2016.

[66] Y. Xie and L. Breen, "Greening community pharmaceutical supply chain in UK: a cross boundary approach," Supply Chain Management Review, vol. 17, no. 1, pp. 40-53, 2012. 


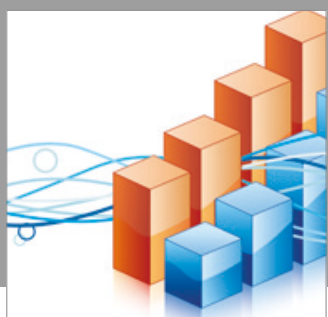

Advances in

Operations Research

vatersals

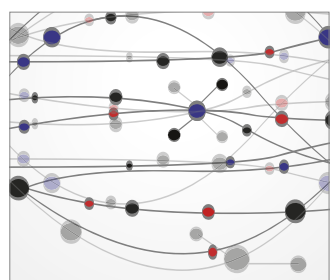

\section{The Scientific} World Journal
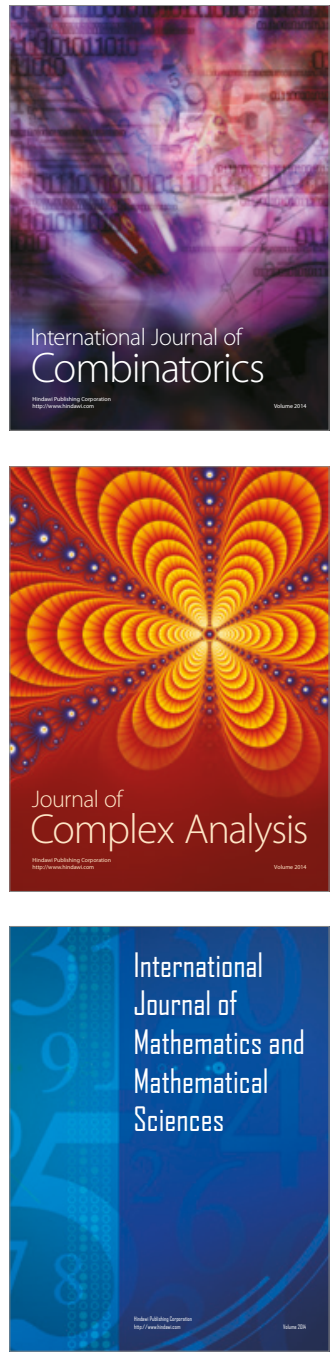
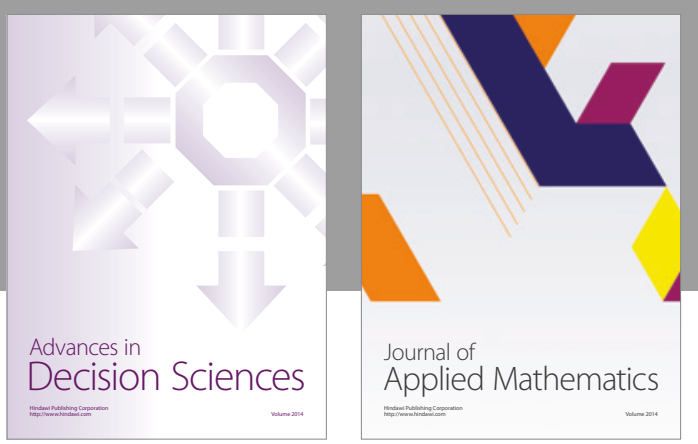

Algebra

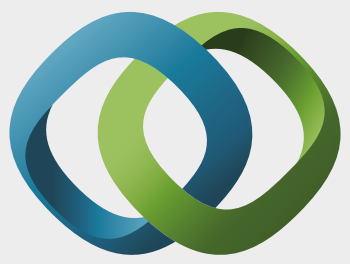

\section{Hindawi}

Submit your manuscripts at

https://www.hindawi.com
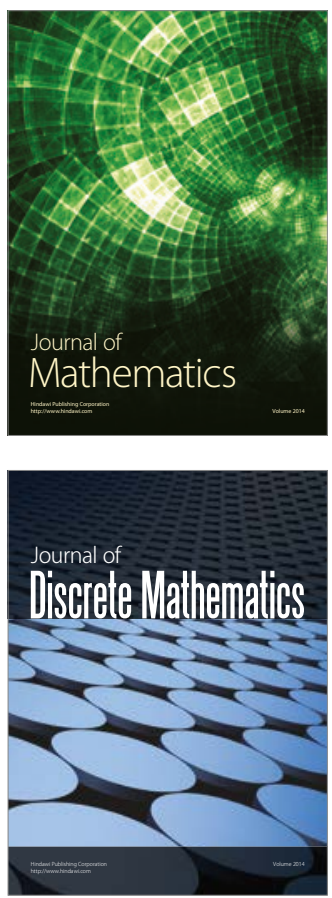

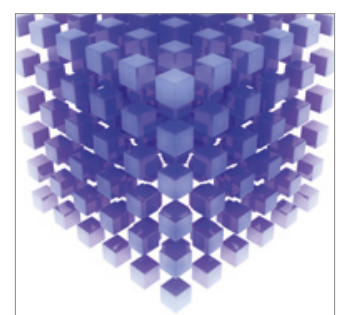

Mathematical Problems in Engineering
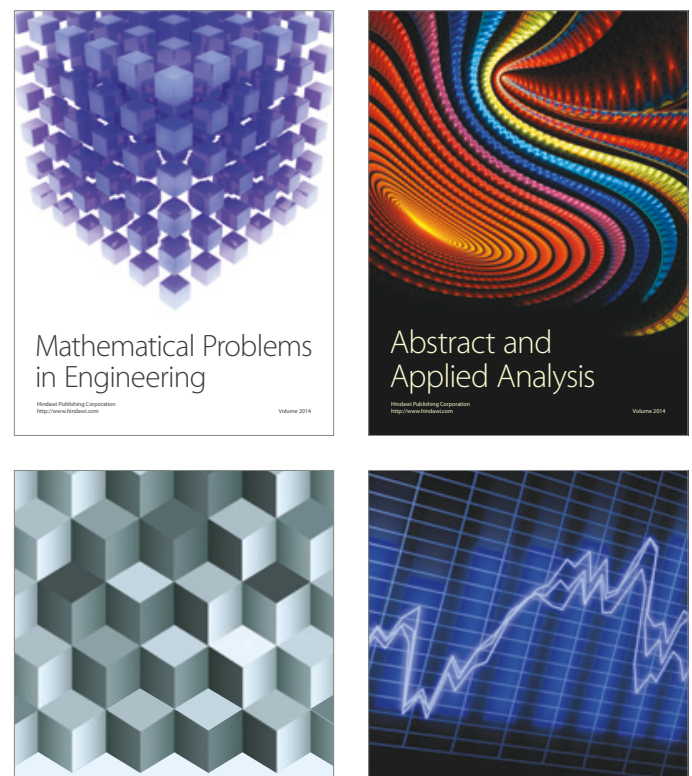

Journal of

Function Spaces

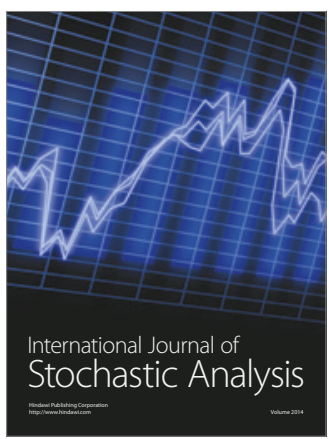

Probability and Statistics
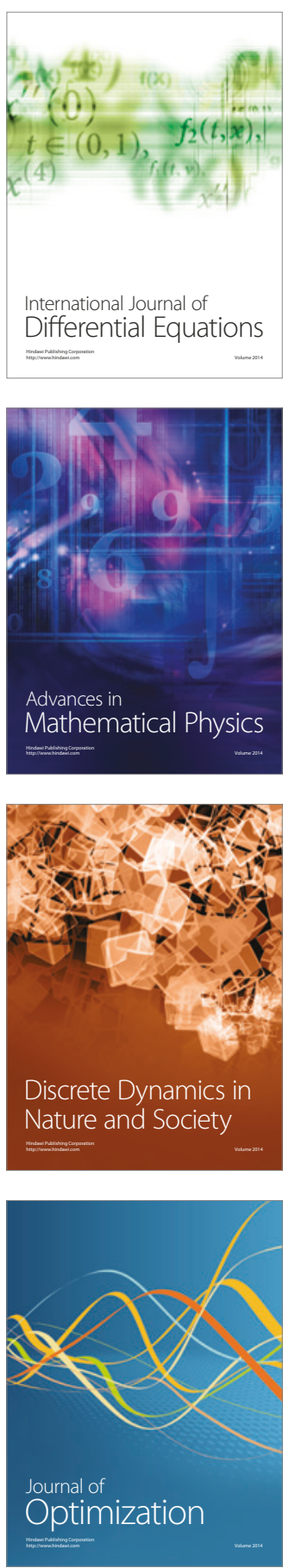